\title{
Women, Wellbeing and the City: A Model of Participatory Health Research Exploring Physical Activity in Black and Minority Ethnic Communities (BAME) Communities.
}

Denise Peerbhoy ${ }^{\mathrm{a}}$, Massoumeh Minou ${ }^{\mathrm{b}}$ and Gareth Stratton ${ }^{\mathrm{b}}$

${ }^{a}$ Mental Health, Berkshire Healthcare Foundation Trust, Bracknell, UK

${ }^{b}$ Sport and Exercise Science, Swansea University, Swansea, UK

\section{Abstract}

Objective: To document a partnership working process from a cross-sectoral and crosscultural participatory health research study focused on promoting physical activity among women from Black and minority ethnic backgrounds.

Design: A participatory health research paradigm was used to support this pilot feasibility study into partnership working for health promotion. Action research and community development principles underpinned the design, delivery and interpretation of findings from a community-based survey, data from 4 focus groups, and bespoke interventions. Setting: Community Groups from education, leisure, health and religious community sectors, and charity sectors, in the City of Liverpool met in different venues representing those sectors.

Methods: Reflection on the process of community-engagement in a research study guided by socio-ecological model, community development and action research principles.

Results: Seven emerging collaborative processes based on effective partnership working, capacity-building practice, and sustaining health and wellbeing, evolved from a partnership between a Community Researchers Advisory Group and a Partners Advisory Group. Black and minority ethnic 'community connectors' were key to obtaining feedback from 213 women from 16 ethnic groups, which influenced the development of bespoke interventions and local sport and physical activity long-term policy, as one means of reducing social inequalities for women from Black and minority ethnic backgrounds.

Conclusion: This feasibility study demonstrates the effectiveness and limitations of partnership working as a public health tool. The local Sport and Physical Activity Alliance and council department worked together to promote the -sustainability of Black and Minority Ethnic (BAME) focused programmes as part of their governance and policy framework.

Keywords: BAME, Participatory Health Research, Obesity, Physical Activity, Partnershipworking.

\section{Corresponding author}

Denise Peerbhoy, Berkshire Health Foundation Trust, Talking Therapies, Bath Road, Thatcham, Berkshire, RG12 1BQ, UK

Email: denise.peerbhoy@berkshire.nhs.uk, denisepeerbhoy1@gmail.com 


\section{Introduction}

This paper documents how a community-based participatory health research project worked with the local community to increase participation in physical activity in Liverpool, UK. Core values of collaborating with the community, working through solutions together (deliberation), and engaging in dialogue iteratively (Springett, 2017) were central to the research.

There is a strong evidence-base showing that physical activity (PA) is good for both psychological and physical health (UK Chief Medical Officer, 2020; Penedo and Dahn, 2005), with Public Health England suggesting specific levels of PA for significant health benefits (Public Health England, 2019). Despite a number of public health campaigns to increase physical activity, women are less likely to include physical activity as part of their lifestyle (Department for Health, 2016) with this being more pronounced and having considerable impact on health and wellbeing in those from Black, Asian and minority ethnic (BAME) populations (NHS Health and Social Care Information Centre, 2005). The reasons for low rates of physical activity are complex (Koshoedo et al., 2015) but are referenced by social inequity amongst BAME and immigrant populations in the UK with major consequences for health and wellbeing (Platt, 2002; Raleigh and Polato, 2004).

A decade of multi-agency approaches to obesity prevention in Liverpool demonstrated some beneficial impacts (Department of Health ${ }_{L^{-}}$2013). However, given that one indicator associated with physical activity is weight, the city of Liverpool UK has shown an increase in population weight and obesity in recent years, with some minority ethnic groups showing obesity levels above those of the general population (Health and Social Care Information Centre, 2015). Relevant to this research, local trends showed an increasing immigrant population in 2008 over a seven-year period (Office for National Statistics, 2009) and highlighted the scale of demand for health promotion activities based upon specific population needs. In addition, this research was aligned with a national strategy focused on reducing unemployment and crime and improving health and wellbeing in the city of Liverpool.

A key stimulus for the research was development of the Kensington Women Get Lively survey and ongoing recognition that women are less physically active than men as documented above. The theoretical background to the research was twofold: socioecological and participatory based. This paper describes the participatory process, with the survey content and outcome data being documented elsewhere (Minou, 2011). A number of factors influenced the choice of health research model used in this study. First and foremost, we wanted to show respect for different knowledge bases in a diverse and multicultural society. Secondly, we were committed to addressing social inequalities and injustice (Tineke and Cooke, 2017). Thirdly, our goal was to connect to appropriate community stakeholders, based on evidence concerning the impact of policy, physical environment, sociocultural and intrapersonal factors on people's ability to be active (Sallis and Owen, 2002), and the interplay between these factors (Peerbhoy et al., 2008).

From the outset, the aim of Liverpool John Moores University (LMU), as a facilitator of a community-based commission, was working with community assets to support the 
promotion of health and wellbeing for Black and minority ethnic (BAME) populations, and encouraging appropriate partnerships for this purpose. Within this context, a partnership can be described as an alliance of people and organisations from multiple sectors, working together to achieve a common purpose in tackling challenging public health issues (Mays and Scutchfield, 2010). In this study, community assets were considered a participatory health resource and refer to what currently exists and can be used to enhance the life of a community (Kretzmann \& McKnight, 1993). Here, it was recognised representative members of the BAME community had the potential to reach out to the wider BAME population but that this had not been utilised in understanding and encouraging PA in the community.

As part of a consultation phase, initial contact was made by the first author and a doctoral student (the second author) with the Kensington Rfegeneration coordinator to assess the feasibility of a participatory health model. Stakeholders from local projects and cultural organisations were invited to initial meetings to ensure a wide representation of BAME participants, with the university taking advice from the Women's Health Information Service Centre (WHISC) about appropriate local BAME representation. During the consultation phase, project aims and objectives, timescale, budget, management, coordination and responsibilities were discussed (Table 1). Stakeholders from different sectors were invited to discuss the feasibility of conducting a survey which explored women's engagement in PA, and the roles and responsibilities of invested parties. A Community Researchers Advisory Group (CRAG) and a Partnership Advisory Group (PAG) were formed (Figure 1). The PAG comprised members from education, leisure, health and the community sectors and was chaired by the first author. The CRAG comprised staff and volunteers from the voluntary sector, and representatives from the research team. The group was chaired by the WHISC. Representatives from this service, Kensington Regeneration and the university sat on both groups.

Figure 1 about here

The following objectives for the project were formulated:

- To work transparently using a socio-ecological model and participatory health research paradigm, collaborating with different stakeholders, forming partnerships, building trust and involvement at all stages of the research. Central to this work was a collaborative approach with knowledge being constructed relationally and through dialogue.

- To demonstrate the feasibility of a partnership approach in exploring the extent of participation in PA and perceived barriers and motivations to participation of women from BAME groups, through the development and delivery of a survey and follow-up focus groups. Central to this was consultation with local women and partners to explore specific ethnic identity category response items, and specific questions about physical activity that could be focused on in a survey, demonstrating participatory health research as a valuable public health tool.

- Through collaboration and dialogue with community and cultural organisations to review and disseminate findings from the survey locally, with the purpose of devising and implementing bespoke interventions for the female BAME population. 
The objectives were developed from the partnership working process, as part of the consultation phase, yet are placed here to emphasise the importance of doing this in a participatory health research context.

\section{Methods}

\section{Research Paradigm and Principles}

This four-month feasibility research project was rooted in a participatory health (PHR) paradigm (ICPHR, 2013), and encouraged the participation of women from BAME communities in research and engagement in PA. It was conducted collaboratively by stakeholders from the education, leisure, health and community sectors (Figure 1). The research is innovative in its cross-sectoral and cross-cultural approach to data collection and review, and as an area-based investigation gathering quantitative and qualitative data from women from BAME groups. There was intention for action research theory (Lewin, 1951) to guide the research structure, which in turn would mutually influence collaboration between partners, and future community action and programme implementation to promote health at the individual, community and policy levels.

From the outset, we focused time and effort on the following success factors of health promotion partnerships: information flow, communication, participation benefits, logistics of practice, understanding and sense of ownership (Ansari et al., 2010). We were also mindful of advocated principles for working with minority ethnic communities by using community resources to increase accessibility, identify and address barriers to access, encourage the use of appropriate language strategies to promote understanding and learning (Netto et al., 2010), and to enhance capacity building for increasing PA in BAME communities (Such et al., 2017).

\section{Stages in the participatory health research}

Seven Collaborative Processes (CP) (Tables 1-3) evolved during the course of the research as a result of a partnership between a CRAG and a PAG (Figure 1). Within each process were tangible, concrete and more measurable outcomes. The collaborative processes are summarised as follows.

\section{Phase 1}

Consultation and initiation of partnership working - establishing partnership groups and aims and objectives of the research.

\section{Phase 2}

Development of a bespoke survey to measure current PA, barriers and facilitators to PA in women from BAME communities, together with capacity-building for survey delivery and data recording. Capacity building for survey delivery was focused on communication messages to the local population, whilst data-recoding capacity-building focused on proving information about operational logistics about recording strategy and process. 
Phase 3

Reflection on findings and dissemination.

The above phases are documented on a research timeline (Figure 2) delivered over an intensive 4-month period.

Insert figure 2 about here

Permission was given by the local New Deal Commission (Liverpool City Council 2008) for the conduct of this research, and ethical approval was provided by Liverpool John Moores University research ethics committee as part of doctoral study undertaken by the second author.

\section{Findings}

\section{Effective Partnership and Collaboration}

Insert tables 1-3 about here

Insert Table 4 about here

\section{Discussion}

\section{The effectiveness of partnership working}

The research described in this paper provides a case study of how different health professionals and community advocates can translate objectives into service delivery (Gates, 2017). A participatory health research paradigm proved to be a feasible model for the population under study. The effectiveness of the approach was shown through a commitment to collaboration and a partnership network of communication and activity that recognised and valued community assets, and worked with interdisciplinary knowledge, input and coordination across different sectors.

Given that existing surveys often elicit perceptions of PA as part of a larger package of lifestyle questions, and use closed and multiple-choice type questions which are not always as sensitive to local concerns (Roberts and Marvin, 2011), the development of a bespoke survey was felt necessary. In devising the survey questions, 'healthy negotiation' (Table 1) took place between stakeholders and community groups, in pursuit of the community researchers' advisory group concern to ensure appropriateness of wording, specific questions and inclusion of specific ethnic groups. Here community relationships and opinion were given priority over existing categorisation systems or the statistical requirements of partner organisations. In alignment with the second objective of this research, two hundred and thirteen women, from sixteen different ethnic groups across Liverpool were reached by the survey (Table 4), with the research providing support for an integrated approach to understanding what was likely to increase PA among women from BAME groups. 
Partners, through their actions, trusted that a collaborative and participatory approach, would prove valuable in enhancing wellbeing at community level. Three decades of cultural regeneration in Liverpool, which has included programmes focused on improving health and wellbeing, set a healthy precedent for such a collaborative relationship. Settings without such a legacy may find this model for tackling health inequalities more challenging.

\section{Capacity building development: sharing and learning, in partnership}

Data collection was grounded in community research activity and underpinned by actionresearch and community development principles. Learning from successive stages between stakeholders informed future activities and research developments (see Tables 1-3). The research team from the university which formed part of the PAG was responsible for a) liaising with the WHISC management and community researchers throughout the research process; b) providing training on survey delivery and recruitment of participants; c) discussing issues regarding the recruitment of participants; d) designing the survey; e) overseeing training and data-input by community volunteers from WHISC, and providing advice and training on collecting, collating and analysing data, whilst taking the lead on data analysis; f) preparing a final project report and encouraging local and wider dissemination of findings.

Representatives from the university and WHISC connected the PAG and CRAG, with Kensington Regeneration supporting the participatory research process and individual projects. Although offering a research expert role, the university team considered negotiating between different organisation and groups offered a role commensurate to that of a stakeholder through joint participation in meetings and research activity. Such a role, as a negotiator of consensus and a broker between groups triggered less criticism, more collaboration and greater proactivity than might otherwise have been the case.

All partners acknowledged the expertise and skill of community volunteers and supported them as much as possible. The university team provided training in data collection and analysis, facilitating the work of the CRAG. WHISC validated community involvement (through payment for volunteers and accreditation); particularly in view of the organisation's strength in accessing the local population through its social, cultural, language expertise and connection with ethnic communities was critical for data collection and.

Overall, the research created a platform that could serve as the foundation for community based projects by engaging community members who were not experts in the field of PA but who were assets to the participatory health research project, and could act as agents of social capital. Crucially, representatives of 16 BAME populations acted as "community connectors", supporting the participatory health research by promoting and communicating details of the project within their respected BAME groups and connecting the community and researchers together. In recompense, this process also provided a positive role and sense of purposefulness for the community connectors. 


\section{Limitations and strengths}

Limitations to our method derive from the naturalistic setting and focus of the research. Using criteria of credibility, transferability, dependability, confirmability and auditability relevant to naturalistic evaluations (Philips and De Vet, 2017), we reflect on the rigour of the research. This research worked toward a specific set of objectives and engaged multisectoral stakeholder participation in response to a local commission and set of priorities (credibility). It implemented training and capacity building for collaborative design, datageneration and survey interpretation with community partners and stakeholders; with checks by the academic lead and Women's Health and Information Service Centre (WHISC), community-volunteer lead, and triangulation between all stakeholders (credibility).

On reflection, two aspects of this study require modification and change should the work be repeated. First, the focus groups were small and lacked interpreters to promote conversation and learning at a deep level. In hindsight, it would also have been beneficial for focus groups to be facilitated by more CRAG members from BAME populations, either by themselves or with researchers. Second, due to the limited scope of this research, there was an informal check by the second author on the confidence of 'community connectors' at delivering the survey. However, there was no systematic assessment of their skills or the challenges experienced encountered by community connectors from the WHISC during their involvement. This would have provided an understanding of any sense of ownership and aspects important to successful partnership working. It is understood that WHISC held a debrief session with participants with no major issues being reported.

This paper provides a detailed account of different aspects of collaboration across the participatory health research case study. It offers an approach to health promotion working that can be applied to other cities and environments where there is appropriate infrastructure (transferability). Findings from such studies could inform the design of community-based intervention to ensure barriers to PA amongst BAME populations are addressed. Importantly, stakeholders in this study felt that the key pre-defined aims and objectives of the research had been met, and the collaborative nature of this research was well received.

The partnership between the CRAG and PAG encouraged the valuing of community assets, community language and thought, and diverse skills of stakeholders. It did this by sharing information, promoting transparent communication, validating volunteer participation, and working collaboratively on all aspects of the research process. Training and capacity building meetings and dissemination activities in BAME cultural organisations enabled different sectors to come together. The importance of power dynamics in participatory health research is recognised (Wallerstein et al., 2018), with this research focused on providing a platform for shared ownership, power, and equality between stakeholders. (Tables 1-3). Although by stealth, the first two authors believed their asian and arabic ethnicity assisted in connecting with the CRAG, and with women from a BAME background during focus group facilitation. 
Ultimately, the participatory health research process provided an innovative and costeffective way of researching a public health issue (Crone and Baker, 2012), without compromising research objectives, and while valuing social capital and partnership working. The project infrastructure created opportunities for individual learning via increased participation in research as result of capacity-building, and the potential for women from BAME backgrounds to engage in PA from developed projects.

\section{Sustaining health and wellbeing in BAME populations}

Given the case study's adherence to successful partnership working principles (Netto et al., 2010; Ansari et al., 2010) it is hoped that the partnership will develop and grow. A significant outcome of the research was that those at strategic and grassroots levels were able to develop a shared understanding of what they considered 'of merit and worth' in the research, and its commitment to working with BAME groups in culturally sensitive ways. The Women get Lively study was highlighted as exemplary in the local authority's 'Be Activity: Be Healthy' strategy (Liverpool Department of Public Health, 2012). Moreover, the Liverpool Sport and Physical Activity Alliance stressed the importance of sustainability for Black and Minority Ethnic (BAME) focused programmes in their governance framework and policy (Liverpool Department of Public Health, 2014).

\section{Conclusion}

In summary, this study highlights the strength of the participatory health research model in developing effective partnerships, aimed at increasing wellbeing for women. Work was characterised by a strong consultation process; ideological and practical support for a community development model, and participatory approaches by multiple partners with varying knowledge and skills; and willingness to share resources and existing community assets to understand local BAME populations and co-create bespoke PA interventions. It is hoped that the established and new partnerships will develop over time to reduce health inequalities for women.

\section{Competing Interests}

None declared

\section{Acknowledgments}

We thank the Women's Health Information Centre (WHISC) and members of the BAME communities linked to this organisation whose input and involvement was critical to its success. We also thank members of the local BAME population for participating in this research. 


\section{References}

Ansari W and Osrochi R and Phillips C (2010) One size fits all partnerships? What explains community partnership leadership skills? Health Promotion Practice 11: 501-514.

Crone D and Baker C Promoting Health (2012) Embracing alternative evaluation designs, working practices and service delivery modes. Journal of Public Health 20 (5), 477478.

Gates E (2017) Learning from seasoned evaluators: Implications of systems approaches for evaluation practice. Evaluation 23: 152-171.

Department of Health (2016) Health matters: getting every adult active every day. London: Department of Health.

Health and Social Care Information Centre (2015) Statistics on Obesity, Physical Activity and Diet: England 2015. London: Health and Social Care Information Centre. Available at:

https://mrc.ukri.org/documents/pdf/statistics-on-obesity-physical-activity-and-diet/ (last accessed 1 July 2020)

International Collaboration for Participatory Health Research (ICPHR) (2013) Position

Paper 1: What is Participatory Health Research? Berlin: International Collaboration for Participatory Health Research.

http://www.icphr.org/uploads/2/0/3/9/20399575/ichpr_position_paper_1_defintion__version_may_2013.pdf (last accessed 1 July 2019)

Koshoedo S and Paul-Ebhohimhen and V Jepson R and Watson M (2015) Understanding the complex interplay of barriers to physical activity amongst black and minority ethnic groups in the United Kingdom: a qualitative synthesis using metaethnography. BMC Public Health 15: 643.

Kretzmann J. \& McKnight J. (1993) Building communities from the inside out. Chicago, IL: ACTA Publications.

Lewin K (1951) Field theory in Social Science. New York: Harper and Row.

Liverpool Department of Public Health (2012) Liverpool Active City 2012-2017 Be Active:

Be Healthy. Creating a Moving Culture (2012). Liverpool: Department of Public Health. available at:

https://www.liverpoolccg.nhs.uk/media/1070/liverpool-active-city-strategy-20122017.pdf (accessed 1 July 2019)

Liverpool Department of Public Health (2014). Liverpool Active City Living Well Summit Edition. Physical Activity and Sport Strategy 2014-2021. (2014) Liverpool Department of Public Health available at:

https://liverpoolccg.nhs.uk/media/1759/liverpool-active-city-pas-strategy.pdf (accessed 1 July 2019)

Department of Health (2013). Liverpool Primary Care Trust. Department of Health Annual Report and Accounts 2012-13 London: Department of Health. available at: https://assets.publishing.service.gov.uk/government/uploads/system/uploads/atta chment_data/file/253402/Liverpool_PCT_Annual_Report_and_Accounts_201213.pdf (accessed 1 July 2020)

Mays G P and Scutchfield F D (2010). Improving public health system performance through multiorganisational partnerships. Preventative Chronic Diseases 7(6):1-8. 
https://www.ncbi.nlm.nih.gov/pmc/articles/PMC2995603 (last accessed 1 July 2020)

Minou M (2011) Physical Activity Promotion of Ethnic Populations in Deprived Communities: From Determinants to Intervention. Available at:

http://researchonline.ljmu.ac.uk/6014/1/536145.pdf (last accessed 1 October 2019)Netto G , Bhopal R, Lederle Net al. (2010) How can health promotion interventions be adapted for minority ethnic communities? Five principles for guiding the development of behavioural interventions. Health Promotion International, 25(2):248-57.

Health and Social Care Information Centre (2005). Health Survey for England 2004 : The Health of Minority Ethnic Groups. London: Health and Social Care Information Centre.

Office for National Statistics. (2009). National population projections: 2008-based projections. Population Trends. London: Office for National Statistics. Available at: https://www.ons.gov.uk/peoplepopulationandcommunity/populationandmigration /populationprojections/adhocs/0063472008basednationalpopulationprojectionsuk mid2008tomid2108 (last accessed 1 July 2020)

Peerbhoy D and Majumdar A and Wightman, et al. (2008) Success and Challenges of a community lifestyles intervention in Merseyside (UK) to target families at risk from coronary heart disease. Health Education Journal 67(2): 134-147.

Penedo F and Dahn J (2005) Exercise and wellbeing: a review of mental and physical health benefits associated with physical activity. Current Opinion in Psychiatry 18:189-193.

Philips T and De Vet J (2017) Towards a rigorous practice: A framework for assessing naturalistic evaluations in the developmental sector. Evaluation 23: 102-120.

Platt L. (2002) Parallel lives: Poverty among ethnic minority groups in Britain. London: Child Poverty Action Group..

Public Health England (2019.) Physical Activity. Applying all Our Health. London: Public Health England. Available at:

https://www.gov.uk/government/publications/physical-activity-applying-all-ourhealth/physical-activity-applying-all-our-health. (last accessed 1 July, 2020)

Raleigh V and Polato G (2004) Evidence of health inequalities. London: Healthcare Commission.

Roberts K and Marvin K (2011) Knowledge and Attitudes towards healthy eating and physical activity. What the data tell us. National Obesity Observatory. Available at:http://www.noo.org.uk/uploads/doc/vid_11171_Attitudes.pdf

Sallis J and Owen N. Ecological models of health behaviour (2002) In Glanz K, Rimer BK, Lewis FM et al. Health Behaviour and Health Education: Theory, Research, and Practice. CA, San Francisco: Jossey-Bass,462-84.

Springett J (2017) Impact in participatory health research: what we can learn from research on participatory evaluation. Educational Action Research 25(4): 560-574.

Such E and Salway S and Copeland R and Haake S and Domone S and Mann S A (2017) formative review of physical activity interventions for minority ethnic populations in England Journal of Public Health 39(4) 265-274.

Tineke A and Cook T and Ramgard K and Harris E and Wallerstein J (2017) Social Impact of participatory health research: collaborative non-linear process of knowledge mobilization Education Action Research 25(4):489-505. 
Department of Health and Social Care (2020). Physical activity guidelines: UK Chief Medical Officers' report. London: Department of Health and Social Care. available at:

https://www.gov.uk/government/news/new-physical-activity-guidelines-issued-byuk-chief-medical-officers (last accessed 1 July 2020)

Wallerstein N, Muhammad, M., Sanchez-Youngman, S., Rodriguez Espinosa, P, Avila M. et al. (2019) Power Dynamics in Community-Based Participatory Research: A Multiple-Case Study Analysis of Partnering Contexts, Histories, and Practices Health Education \& Behavior, 46(1S) 19S-32S. 


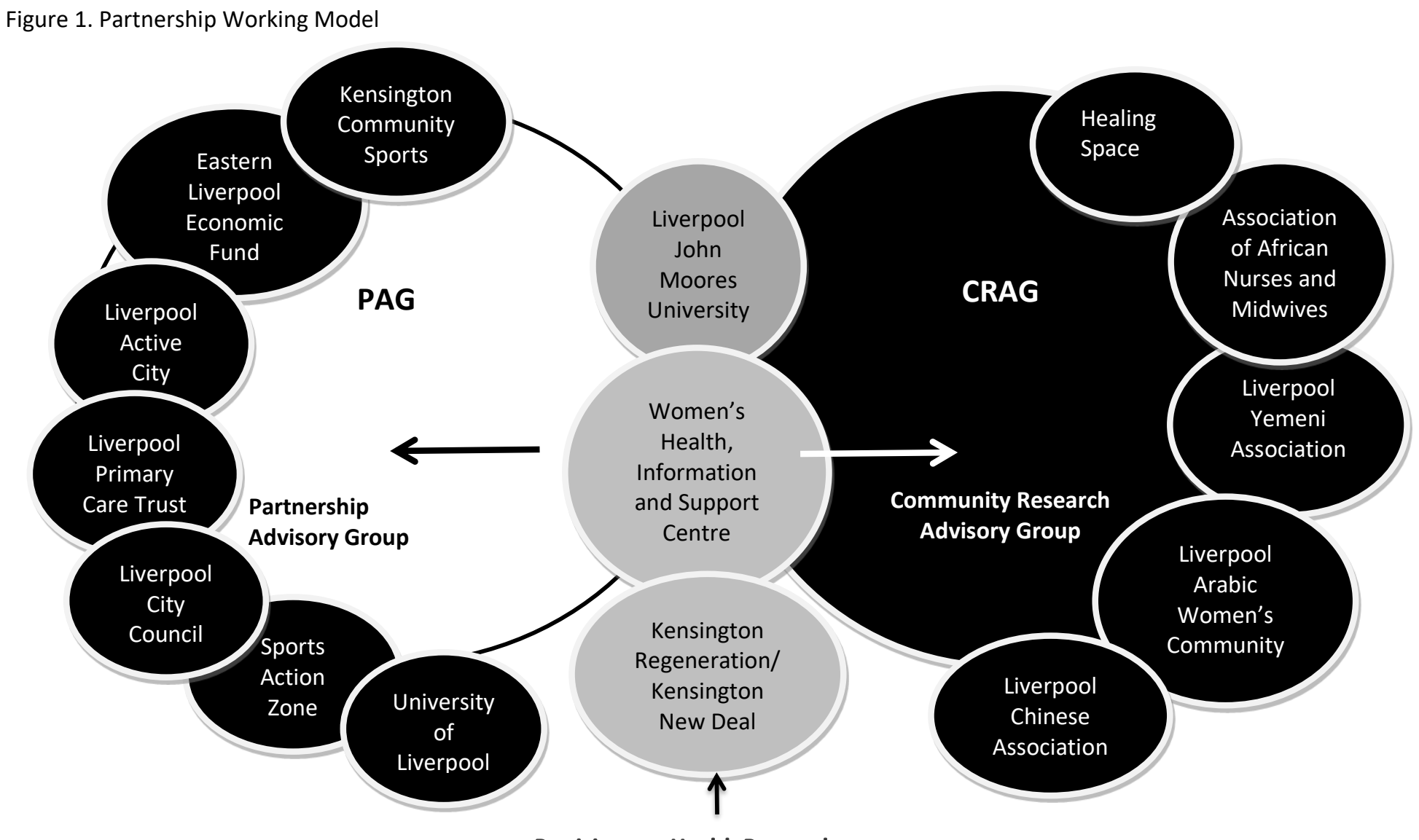

Participatory Health Research 
Figure 2 Kensington Women Get Lively Timeline

Collaborative Process (CP) 1-7

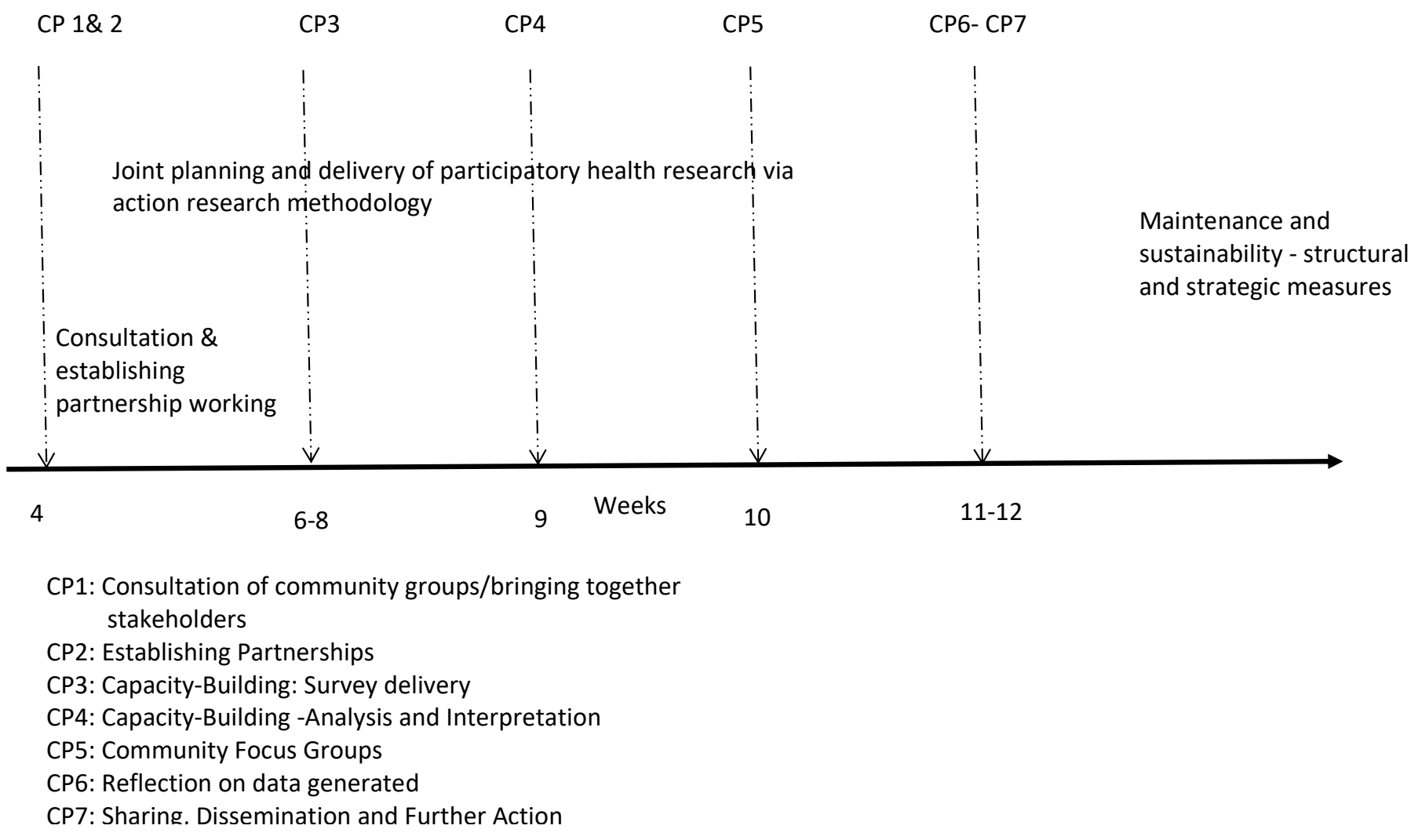


Table 1. Ethnicity of BAME groups reached by survey

\begin{tabular}{lc}
\hline Ethnicity & Percentage \\
African & 32 \\
Arabic or British Arabic & 18 \\
British & 10.3 \\
Chinese or British Chinese & 10.1 \\
Other Asian background & 9.0 \\
Indian & 5.1 \\
Other European & 3.0 \\
Other White & 3.1 \\
Other ethnic group & 2.8 \\
Caribbean & 1.1 \\
Other mixed background & 0.6 \\
White and black African & 0.5 \\
Pakistani & 2.2 \\
Bangladeshi & 0.6 \\
Irish & 1.1 \\
& \\
Ethnicity was not provided by 15 people. & \\
\hline
\end{tabular}


Table 12. Collaborative Processes (CP) 1-2: Partnership working establishment and design of a bespoke survey

\section{CP 1: Consultation}

-BAME groups and those working with BAME groups from the community were invited to a potential stakeholder workshop at Liverpool John Moores University (LMU), and the commission idea presented with messages of partnership working.

-A Community Researchers Advisory Group (CRAG) and Partnership Advisory Group (PAG) were formed (Figure 1). It was agreed by PAG and CRAG that the role of LMU University was to liaise with WHISC management and, community researchers during the course of the research; provide a capacity-building and consultancy service in view of construction, implementation, and lead on the interpretation of data whilst sharing this with both advisory groups, with agreed documentation of the research through intermittent and final summary report.

-Research objectives were formulated between partners with the hope of embedding a message of responsibility for all partners in the research process and embedding a sense of ownership for this and future possible programmes.

CP2: Design of a Bespoke Survey

-Agreement by PAG and CRAG partnership to create a bespoke survey to seek viewpoints from people from BME backgrounds about their involvement in PA.

Healthy Negotiation Process

- Agreement that PA referred to behaviour that included walking and gardening (as it was felt this would be a relevant definition for many BME members according to CRAG group), as well as more structured physical activities.

-It was accepted from CRAG feedback that current wording of existing surveys, which often used the word sport, would impede participant response.

-The 'Women Get Lively Survey' name was established between partners and there was an understanding that the design structure would explore: current involvement of women in PA (self and other); awareness of facilities and opportunities in the area; identification of actual and perceived barriers and constraints to engaging in PA (self and others); perceived opportunities to increase participation in sport and physical activities for women in Kensington and the local area.

-It assessed how the level of PA is affected by socio-demographic and environmental factors by including questions aimed at obtaining personal views about PA; community cohesion and awareness of community events aimed at promoting PA.

- Survey questions were developed between the Community Researchers Advisory Group (CRAG) and Partners Advisory Group (PAG), with the CRAG forming questions which were then put to the PAG, which were accepted, rejected, or modified. The survey consisted of demographic questions (age, ethnicity, post code) plus a

combination of multiple choice and open-ended questions to explore the above stated issues. A decision was made to have more open-ended questions rather than multiple choices to create less force and avoid biasing the responses and to ask respondents if they would be willing to be contacted again for further research purposes and to provide contact details.

-A decision was made based on 'sensitivity', by both advisory groups, not to ask women precise questions about the amount of time they were involved in PA given the strong notion that this would lack meaning on a cultural level. Another area of considerable debate was ethnic identity (See Figure 2 for agreed identities). More general questions about PA, with a breadth over depth approach to information collection, given the pilot nature of this investigation, were agreed upon by stakeholder groups. Community perception on practical and semantic issues regarding the survey, tended to be favoured over health academic and health authority agendas. 
Table 23. Collaborative Processes 3-5. Pre- and Post-Survey Capacity-building and Survey Delivery to BAME populations

$$
\text { CP3: Capacity-Building: Survey Delivery }
$$

- Two researchers (first two authors), the Kensington Rregeneration project coordinator and the WHISC project manager held training sessions for community researchers to conduct the survey. There were 3 training sessions which lasted approximately two hours each and they took place in a local job centre in Kensington. Sessions focused on the rationale of the project, structure, content and delivery of the questionnaires.

- Community volunteers were trained on how to approach and recruit participants and how to conduct the survey. In particular, to explain persuasively to potential

respondents to answer questions as a means of obtaining a perspective about PA from the local BME population in order to help them devise ways of improving PA uptake.

- Practicing the questionnaire with follow up discussion and debate focusing on potential problems identified with delivery challenges was included in training. Noted

problems related to differences between face to face and telephone interview and language and interpretation of questions.

- Consistency, Interpretation and approaches to delivery were agreed on by the primary researchers and community volunteers.

-Volunteer's confidence in delivering the survey was monitored with all stating they felt sure of their role.

-An opportunistic sampling strategy was used. CP 4: Survey Delivery

- The survey was administered by volunteers from the CRAG, many of whom were either working or had previously worked for WHISC.

- They approached people mostly from the BAME population in churches, their houses, offices, community centres, and occasionally via the phone to conduct the interviews. Ninety-six per cent of people were contacted face to face.

- Some questionnaires were sent out to people by post providing them with a stamped addressed envelope.

-With direct face to face contact information was imparted in mother tongue to participants to facilitate increased understanding, and responses were recorded in English.

- Community volunteers were also trained on how to approach and recruit participants and how to conduct the survey. Interviewers were required to explain persuasively to potential respondents to answer questions as a means of obtaining a perspective about PA from the local BAME population to help them devise ways of improving PA uptake.

CP 5: Capacity-Building - Coding, Analysis and Interpretation

- Community researchers were given instructions by the research team on which question responses they should record, and specific codes assigned to specific responses.

-All responses which could be quantified were entered into an excel database with which community researchers were familiar.

- The LMU research team spot checked the data, referring to 20 respondents, and transferred the data and transferred the data to statistics analysis software (SPSS version 17.0) for frequency and correlation analysis.

-Agreement by research team and community volunteers about questionnaires that would be excluded.

- Findings were reported back to the CRAG and PAG groups and discussed further in relation to the needs of the community. 
Table 34. Collaborative Process 6-7. Reflection on survey findings with the community: meaning, dissemination and future direction. CP 6: Community Focus Groups

- It was agreed by the PAG and CRAG that WHISC volunteers would work with the LMU research team to facilitate focus groups, with anticipated translation

and cultural guidance. WHISC and Kensington Rregeneration chose the venues for focus groups activity and took the lead for recruiting volunteers. Four focus groups took place across cultural community organisations in Liverpool over four consecutive days.

- Focus groups venues: a local multicultural school , an International Women's day event, a centre providing social and educational activities for the Arabic community, and Asylum Link Merseyside.

- Each group was initially asked a set of questions about PA activity they were currently involved in and what helped or made it difficult for them to be physically active. Further questions explored what type of physical activities people would like to be involved in; ideas for outdoor activities opinions on home-based PA initiatives. Discussion was encouraged with each question. Participants were also asked about the best ways to provide information to them about PA events, and how they could be helped in view of transport issues.

- Focus groups comprised 5-8 people. Focus group participants were not keen on the sessions being voice recorded, hence all responses were recorded on flipcharts by the 2 facilitators (Primary researchers). A WHISC lead volunteer, chosen by WHISC, also conducted one of four focus group. All facilitators were aware of cultural sensitivities based on their own ethnic backgrounds.

-Brief training was provided to volunteer about how to structure the focus groups and enquire further about the survey results.

- Key issues arising were documented by LMU XXXX researcher/volunteer using flip charts, for each group until a saturation point was met; these were then grouped into specific themes by researchers and cross-referenced with partner groups at a stakeholder meeting with consensual agreement by all.

- A total of 17 women from African, Asian, Black British, Arabic, Chinese, and European communities participated in focus groups. All except one of the participants could speak English, with there being a lack of resources to address this.

$$
\text { Data generated }
$$

- Cultural, intrapersonal, interpersonal barriers/facilitation identified about PA participation. Large extent of BAME population not participating in PA (Minou, 2011).

-Preferred activities/interventions:

- Family-based interventions are:

-Activity focused on women-only, parent and child, community-based activity (indoor and outdoor based)

- Desire for a balance between fun and energising/vigorous PA, some of which could be linked to the environment i.e. urban walks or community-based institutions. Consideration of immediate intrapersonal, interpersonal and environment facilitators e $g$ i.e. childcare facilities, transport infrastructure, commitment, motivation, and perceived support 
-International presentation of project (author MM at BASES Annual Conference, Brunel University, London 2008).

-New Deal Commissioners were sent a final research report (by author DP).

- Development of community-Informed interventions and validation of new partnership groupings e.g. LAC, WHISC, ELECT, LMU partnership for programme development:

-Implementation of a six-week Pilates programme in a local school, based on economic movement practice. A core group of 10-12 women from African, Asian and European ethnicities attended and reported on their enjoyment, benefit and desire for further sessions.

-Future plans: a 6-week course focused on pelvic floor health, core stability, strength, and flexibility, for women to feel more comfortable using household items to increase PA.

-Tapping into community resources: a) Liverpool Active City area coordinators b) Use of WHISC database (resulting from Survey/ Kensington Regeneration text service) with participant consent to contact regarding activities/research) c) Accreditation/Validation of community volunteers (payment and community certificate) d) further research facilitation/capacity building by academic partner.

- Sustainability: continued community intervention and research

-Decision to keep open the CRAG, PAG and university research network.

- Findings well received by local Primary Care Trust and Sport and Physical Activity Strategic Alliance reinforcing their strategy of PA for families.

-Findings from this research inform the design of an appropriate community-based intervention - "The Workout Project" targeting women, girls, and disadvantaged groups.

-The 2017 Liverpool Active City Strategy identifies the process of Kensington Women Get Lively as exemplary investigation which underpinned "The Workout Project". 
Table 4. Ethnicity of BAME groups reached by survey

\begin{tabular}{lc}
\hline Ethnicity & Percentage \\
& 32 \\
African & 18 \\
Arabic or British Arabic & 10.3 \\
British & 10.1 \\
Chinese or British Chinese & 9.0 \\
Other Asian background & 5.1 \\
Indian & 3.0 \\
Other European & 3.1 \\
Other White & 2.8 \\
Other ethnic group & 1.1 \\
Caribbean & 0.6 \\
Other mixed background & 0.5 \\
White and black African & 2.2 \\
Pakistani & 0.6 \\
Bangladeshi & 1.1 \\
Irish & \\
Ethnicity was not provided by 15 people. & \\
\hline
\end{tabular}

